\title{
Resumé and an open question
}

Let me give you a very brief upshot of the main findings of this book. I have defended what I called "the success view of ability". On that view ( $\rightarrow$ 5.3),

SUCCESS $_{\text {ABILITY }}$ an agent $S$ has an ability to $\phi$ if and only if $S \phi$ 's in a sufficiently high weighted proportion of the relevant possible S-trigger situations.

An S-trigger situation, on that view, is a situation in which some trigger is present in response to which $\phi$-ing counts as a success.

Abilities and dispositions, I suggested ( $\rightarrow$ 5.4), differ along the success dimension. While it seems plausible that an object has a disposition to $\phi$ if and only if the object $\phi$ 's in a sufficiently high proportion of the relevant possible situations in which some trigger for $\phi$-ing is present, that trigger will have to be an S-trigger in order for that disposition to qualify as an ability.

The most paradigmatic cases of abilities are what I called "agentive abilities" - abilities to perform actions. The S-trigger that matters in the case of such abilities, I argued $(\rightarrow 4.2,4.8,4.9)$, is the (de dicto or de re) intention to $\phi$, or - in exceptional cases - a different intention entirely, where that intention, too, will have to be an S-trigger. Thus, according to the success view of agentive abilities $(\rightarrow 4.10)$,

AGENTIVE ABILITIES. an agent $\mathrm{S}$ has an agentive ability to $\phi$ if and only if $\mathrm{S} \phi$ 's in a sufficiently high proportion of the relevant possible situations in which S intends to $\psi$, where $\psi$ will typically be de dicto or de re identical to $\phi$, and in all other cases be such that $\phi$-ing in response to the intention to $\psi$-ing counts as a success.

The success view is a hybrid of conditional analyses $(\rightarrow 2,6.2)$ and possibilism $(\rightarrow$ 3). On the one hand, it analyzes agentive abilities in terms of a modal tie between the agent's motivation and the corresponding performances, which is a core feature of conditional analyses. On the other hand, it establishes that modal tie by means of restrictions on the possible situations, which is a core feature of possibilism.

The view, I argued ( $\rightarrow 4.3-4.7$ ), is very powerful. It accounts for masks and cases of impeded intentions; it provides an account of degrees and the corresponding kind of context sensitivity of ability ascriptions; it provides an understanding of general as well as specific abilities and the relationship between the two; finally, it provides an understanding of agentive and non-agentive abilities and how they relate. The view therefore meets all of the adequacy conditions for a comprehensive view of abilities that were laid out in chapter 1 .

○ OpenAccess. (C) 2020 Jaster, published by De Gruyter. (cc) BY-NC-ND This work is licensed under the Creative Commons Attribution-NonCommercial-NoDerivatives 4.0 License. 
Some topics are underdeveloped in this book and I want to take the time to mark out one of those topics very clearly in the end. In part, this is for reasons of academic virtuousness, in part, however, it is also because I take this open flank to set a highly interesting agenda for future research.

I have said nothing about the ability to intend. When I talked about agentive abilities, I explained that the success view of such abilities does not run into the problem of the impeded intention $(\rightarrow 4.4)$. The reason it does not run into that problem is that it entails what I called the existential requirement: there has to be a relevant intention situation to begin with, in order for there to be a sufficiently high proportion of performance cases among the relevant intention situations. And this requirement, I laid out, fails to be met in cases in which an agent cannot intend to $\phi$ in the first place. That was all we needed to shield the success view from the problem of the impeded intention. So far, so good, then.

What I haven't talked about, however, is the ability to intend to $\phi$ as such. Quite plausibly, meeting the existential requirement is not sufficient for the having of the ability to intend to $\phi$, after all. The reason is simple. Agents can have the ability to form a certain intention to different degrees. The existential requirement is therefore just as ill-suited as a sufficient condition for the having of the ability to intend to $\phi$ as possibilism was for the ability to $\phi$ itself $(\rightarrow 3.5)$.

That the ability to intend, too, comes in degrees may not be obvious right away, because we usually do not grade the ability to intend. We do not say things like "She is better at intending to cook" or "He is the better intender when it comes to cooking". However, and this is important, the ability to intend can be diminished to varying degrees. And this shows that the existential requirement is only a necessary, but not a sufficient condition for the having of the ability to intend. Let me explain.

So far $(\rightarrow 2.3,4.4)$, we have only ever thought about cases of impeded intentions as an all or nothing matter. The coma patient lacks the ability to raise her arm, while I have it, because she cannot intend to raise her arm, while I can. The brainwashed follower of a cult cannot leave the cult, while the non-brainwashed person can, because the brainwashed follower cannot form the intention to leave, while the non-brainwashed person can. A phobic, to take another famous example, cannot touch a spider, while normal people can, because the phobic cannot form the intention to touch it, while normal people can. In each case, the ability to intend to $\phi$ is fully impaired in one case, and fully intact in the other.

But now think of what we can call a "mild phobic". A phobic, that is, who sometimes, in certain therapy sessions, manages to form the intention to touch a spider. And then does touch a spider! Mind you: her motor abilities 
are not impaired in any way. Compare her ability to touch a spider with the ability of what we can call a "full-fledged phobic". A phobic, that is, who cannot form the intention to touch spiders at all and therefore never manages to touch a spider. It seems clear that one of them is better at touching spiders than the other one. And where does this difference in the degree of the ability to touch spiders stem from? Quite obviously, it stems from a difference in the degree to which they form the intention to touch a spider. That, after all, is the only difference between the two agents.

The problem with the existential requirement is that it cannot capture differences in degrees of the ability to form intentions. As we know from our discussion of possibilism $(\rightarrow 3.5)$, the existential quantifier is ill-suited to do that job. All this is unsurprising. The ability to intend, just like any other ability, will have to be analyzed in terms of the success view, of course. It will be a matter of proportions among properly restricted situations.

Does this lead into a regress? Does the ability to touch spiders require an ability to intend to touch spiders and does that ability, in turn, require an ability to intend to intend to touch spiders, and so forth? It does not. Recall that the success view of agentive abilities is a special instance of the success view of abilities tout court. And that stops the regress.

The ability to touch spiders is an agentive ability. It requires, among other things, that the agent have the ability to intend to touch spiders. ${ }^{1}$ And for that ability, the existential requirement postulates a necessary condition $(\rightarrow 4.4)$. To have the ability to touch spiders, there have to be relevant possible situations in which one forms the intention to touch spiders.

The ability to intend to touch spiders, however, is not itself an agentive ability. Intending is not an action. That is why I formulated the success view of agentive abilities in terms of intentions in the first place, and not in terms of decisions or other mental acts that seem to be actions themselves $(\rightarrow 4.2)$.

The ability to intend will thus have to be analyzed along the lines of the success view of non-agentive abilities. Having an ability to intend to $\phi$ is for the agent to intend to $\phi$ in a sufficient proportion of the relevant possible situations in which some S-trigger for intending to $\phi$ is present. This brings us to the question I have not answered in this book. Which S-trigger matters in the case of intentions? How can we analyze the ability to form an intention? This is a question that has not been answered and one that will have to remain open for the time being.

1 Or form some other suitable intention, which is properly modally linked to touching spiders $(\rightarrow$ 4.8). For reasons of simplicity, I neglect this subtlety here. 
I sympathize with the idea that having an ability to intend to $\phi$ is a matter of intending to $\phi$ in a sufficient proportion of the relevant possible situations in which there is an overriding reason to intend to $\phi$. But this condition is not easily spelled out. Are the reasons which matter motivational or normative reasons? Or are both potential S-triggers? There is obviously some more work to do here, and I cannot say that I have made up my mind about these things.

I'll leave that for another day. Or year. 